\title{
THE RELATION BETWEEN THE CYTO-RETICULUM AND THE FIBRIL BUNDLES IN THE HEART MUSCLE CELL OF THE CHICK.
}

\author{
BY \\ HARRY LEWIS WIEMAN. \\ From the Biological Laboratory of the University of Cincinnati.
}

With 2 Diagrams and 17 Figures.

In the great mass of literature that has appeared on the subject of the striated muscle, no account apparently exists of the histogenesis of the heart muscle cell of the chick. This seems rather strange in face of the fact that the chick always has been the classic subject for embryological research. The present study was undertaken for the purpose of determining the structures existing in the heart muscle cell of the chick, especially for comparison with results of similar work that has already been done on other vertebrate forms.

The particular phase of the histogenesis treated in this paper is the relation between the cyto-reticulum of the embryonic cell and the fibril bundles as found in the adult muscle tissue. To avoid any possible confusion or misunderstanding, a definition of terms here at the outset will perhaps not be amiss.

By cyto-reticulum, the writer means the deeply staining network found traversing the cytoplasm of early embryonic cells. The fibril bundles, corresponding to the "Muskelsäulchen " of Koelliker, 02, are the striated longitudinally disposed masses running the length of the adult cell. Each fibril bundle is composed of more elementary parts called fibrils.

On account of the abundance of material and the ease with which the various stages in the development of the cell can be secured, the chick is very well adapted to a study of this kind. The one serious objection is that the various structures of the cell are not as well differentiated as in some other forms.

To Professor Guyer, at whose suggestion this work was taken up, the writer is much indebted for valuable assistance.

American Journat, of anatomy.-Vol. VI. 


\section{Methods.}

A detailed study of the cytoplasmic structures of the heart muscle cell requires the use of a very high magnification. To secure good definition, it was found necessary to make sections $3 \mu$ in thickness. Sections of 4 to $10 \mu$ thickness were used for general structure and form of the cell. Sections were cut in paraffin.

Of the different fixing agents used, none gave more satisfactory preparations than Kolossow's, 92, solution. None was found to surpass it in faithful preservation and differentiation of the cytoplasmic structures. The tissue is killed and hardened by treatment for 15 minutes with a 1 per cent osmic acid solution. This is followed by immersion for the same length of time in a reducing mixture of pyrogallol and tannin. The tissue is next washed in a 0.25 per cent solution of osmic acid, and then in water. After being passed through graded alcohols, the tissue is cleared in xylol, and embedded in paraffin. This method followed by Delafield's hæmatoxylin or methylene blue, counterstained by 0.5 per cent solution of acid fuchsin in 70 per cent solution of alcohol gave excellent results. The chromatin structures of the nucleus and the cytoreticulum appear almost black, while the undifferentiated cytoplasm is red. Acid fuchsin alone without the nuclear stains also yields good preparations.

One objection to Kolossow's solution is that it does not penetrate rapidly enough, and as a result, especially in adult tissue, the structure of the cells in the interior could not be made out as well as that of those in the peripheral portions of sections.

Another killing fluid which gave good results was Gilson's mercuronitric fixing mixture, followed by iron hæmatoxylin for staining. This method produces more uniformly penetrated preparations, but does not show the cytoplasmic reticulum to such good advantage as the osmic acid method.

Hermann's platino-aceto-osmic mixture was also tried. After treatment with this solution the tissue is stained with alcoholic safranin for 24-28 hours. The preparation is then treated with gentian violet according to Gram's method. This method was not as satisfactory as either of the foregoing.

Picrosulphuric-acetic acid was used with good results where general structure was the object sought. This fluid is made by adding a 5 per cent solution of acetic acid to Kleinenberg's picrosulphuric acid solution. Treatment with the above is followed by staining successively with carmalum and Delafield's hæmatoxylin. 
Besides section methods, maceration was employed. This process was used with satisfactory results in studying the general structure of the entire cell of the adult tissue. Of the various methods tried, treatment for twenty-four hours with a 20 per cent solution of nitric acid, followed by staining with Delafield's hæmatoxylin and acid fuchsin, gave the best preparations.

\section{The Adult Heart-Muscle Cell.}

Examination of the adult tissue shows it to be composed of an anastomosing network of fibers, the demarcation of which into cells is rather uncertain. Apparently a fiber is arranged into cylindrical cells the length of which exceeds many times the diameter. The tapered ends of the cells seem to fit together much in the manner of a dove-tailed joint. The nucleus is oblong in shape and occupies a more or less central pasition, although it is sometimes seen very close to the periphery of the fiber.

The contractile substance, the fibril bundles, consists of deeply staining, longitudinal masses running the length of the cell. Surrounding the fibril bundles and separating each one is the undifferentiated sarcoplasm. Fig. 15 represents portions of two fibril bundles, each with its envelope of sarcoplasm, from the outer wall of the ventricle of the adult fowl. The fibril bundles are divided by cross striations at right angles to the longitudinal axis into alternating broad, deeply staining bands, and narrower bands more lightly stained (Fig. 15, $b l$ ). The broad, heavily stained bands correspond to the "Querscheibe," or "Brücke's doubly refractive substance" of mammalian heart muscle (MacCallum, 97). One of these bands is shown in Fig. 15,a. By carefully focussing up and down, a very narrow, deeply staining band can be seen crossing the light bands. This is the "Zwischenscheibe," or "Krause's membrane," which structure is not very distinct nor readily made out. The continuation of this line, however, can be plainly seen in the sarcoplasm surrounding the fibril bundle (Fig. 15, c). The Querscheibe, as is readily shown in Fig. 15, are slightly larger in diameter than the more lightly stained parts between.

The sarcoplasm surrounding the fibril bundles is not homogeneous, but is divided into disc-like parts. (Fig. 15, d), which could be especially well seen in peripheral cells when partially macerated. In preparations of this kind, the discs were found separate from each other, while the fibril bundles remained intact, that is, they did not break up into corresponding lengths. This it seems would militate against the idea of 
Krause's membrane being continuous with the line of demarcation between two adjacent sarcoplasmic discs. If the latter were the case, it would seem that the fibril bundles should show a tendency to break and separate along the line of Krause's membrane. 'This did not happen. Hence it may be that what appears, to be Krause's membrane may only be the line of demarcation between two successive sarcoplasmic discs seen through the lightly staining parts of the fibril bundles.

Teased tissue showed the fibril bundles each to be made up of smaller longitudinally disposed parts, the fibrils. The fibril bundles were in all cases surrounded by sarcoplasmic discs.

In the adult tissue the fibril bundles are more abundant in the periphery of the cell than toward the center, which is composed for the most part of a network of undifferentiated protoplasm (Fig. 16). This figure represents a longitudinal section through the center of the cell. Part of the sarcoplasmic dises of a fibril bundle is marked $s a$ in this figure.

Cross sections show cells of widely varying diameter. Fig. 17 represents three cells of a medium type. Cells of three and four times the diameter of these are also found. Fig. 17 is exceptional in that it shows the cell boundaries very distinctly. In most cases the cells are so closely applied that it is difficult to distinguish cell walls. These sections show the fibril bundles as dark, deeply staining patches $a$, surrounded by the sarcoplasmic discs, $(s b)$ (Fig. 17). Some of these discs are seen to be further subdivided $(s d)$, into what MacCallum, 97, has described as " small sarcoplasmic discs."

Between the cells as represented in Fig. 17, and connecting them, may be noticed a number of threads $t$, which resemble very much the strands of the reticular structure of the interior of the cell. Just what the origin and nature of these structures are, could not be determined. A study of these structures would doubtless throw some light on the question of whether the heart muscle fiber is a syncytium or not. No structure analogous to the "protoplasmic bridges" of mammalian heart tissue or the "stratum granulosum terminale" (Prezwoski, as quoted by MacCallum, 97, p. 611), of human heart muscle, was found connecting the ends of the cells.

Such, in brief, are the structures met with in the heart muscle cell of the adult chick.

\section{Embryonic Development.}

To study the different stages through which the cell passes in its development, sections from embryos varying in length from $8 \mathrm{~mm}$. (15 somites), to $22 \mathrm{~mm}$. ( 8 days), were examined. Cells characterized by 
a certain structure are not confined to any one stage. In the following account cells are said to belong to a certain stage because they were first noticed in that stage, although they may be, and frequently are, seen in sections from tissue several days older.

Thirty hours (15-somite stage).-Cells of this stage exhibit in longitudinal section a characteristic short, broad, cylindrical form (Fig. 1). The ends of the cell taper rather abruptly from the center. The nucleus (Fig. 1, $d$ ) is large and oval; its short diameter being but slightly less than the diameter of the cell. Large chromatin masses (Fig. 1,b) may be seen as heavily stained, irregularly shaped clumps, and a very fine network traverses the nucleus.

The cytoplasm exhibits a pronounced reticular structure, with large and irregular meshes. At the intersections of the threads of this network, the staining is somewhat heavier, marking off these parts more distinctly than the rest of the reticulum.

Fig. 2 is a cross section through the region of the end of the nucleus. The cytoplasm shows the same reticular structure, the nucleus appearing oval in outline.

Cells of this general description are typical of the heart tissue in its very earliest state of formation. They can be readily distinguished from the unmodified mesenchyme cells, in that they do not show the branched structure of the latter.

Seventy-two hours (3-day stage).-Up to this period in its development, the cell differs but slightly from the description given above. At this time, however, several changes are to be noticed. The cell has become larger and the tapering ends have increased in length (Fig. 3). The points of intersection of the threads of the cyto-reticulum are more distinctly marked than before by accumulations of heavily staining material, spherical in form (Fig. 3,a). These are also shown in cross sections (Fig. 4,a). The nucleus is oval in form though somewhat smaller than in earlier stages. The chromatin masses (Fig. 3, $b$; Fig. $4, b)$ have decreased in size.

Ninety-six hours (4-day stage).-Fig. 5 represents a longitudinal section of a cell of this period. The cell has increased enormously in size, especially in its longer diameter. The deposits on the cytoreticulum are larger and stand out very clearly and distinctly (Fig. 5, a). The meshes of the cyto-reticulum are still very irregular in form. The nucleus does not seem to have undergone the same increase as the cytoplasm, and its chromatin masses have become smaller and more evenly distributed (Fig. 5, b; Fig. 7, b). Fig. 6 shows a cross section above 
or below the nucleus. Some of the meshes of the cytoplasmic network are divided into smaller parts, the small sarcoplasmic discs of MacCallum, 97 (Fig. 6, sd).

120-130-hours' stage.-In Figs. 8 and 9 are shown characteristic longitudinal sections of the cell at this stage in its development. The cyto-reticulum has undergone a striking change. Instead of the irregular structure of the preceding stages, we find a definite arrangement of the network into rectangular meshes. The deposits on the reticulum have increased in bulk in such a way that in longitudinal section they appear as oval-shaped bodies (Fig. 9,a). In Fig. 9, which represents a slight advance in the development of the cell over that shown in Fig. 8, interposed between every two adjacent longitudinal threads of the network bearing the deposits, is to be seen a longitudinal thread the intersections of which with the transverse threads are not marked by heavily staining deposits (Fig. 9, $b x$ ).

This re-arrangement of the meshwork is apparently the first step in the laying down of the fibril bundles. Subsequent development shows that the longitudinal strands bearing the deposits represent the axes of the fibril bundles, and the deposits, the Querscheibe of the adult tissue. The transverse threads (Fig. 9,c) according to MacCallum, 98, give rise (in the mammal) to Krause's membrane. However, this will be referred to again later.

Cross sections (Fig. 10) show the meshes of the reticulum to be further subdivided, but few of the original size remaining. It is to be noted that one or two very large, irregularly shaped meshes are present in this section (Fig. 10, la). Apparently these areas, in later stages, become divided into smaller parts, just as the neighboring cytoplasm has already become divided. Evidently this is the manner in which the growth process in the cell takes place, the cytoplasm in the smaller meshes increasing greatly in bulk and then, by subdivision, producing a number of meshes approximately the size of the first.

The nucleus is oblong in longitudinal section (Fig. 8, $d$; Fig. 9, $d$ ), and roughly circular in cross section (Fig. 10, $d$ ). The chromatin masses are small, although Fig. 10 shows one of considerable size. It appears that Eycleshymer, 04, in his work on skeletal muscle-cells of Necturus, found just the opposite change to take place in the size and distribution of the chromatin granules, $i$. e., in younger stages the karyosomes were evenly distributed in the nucleus, and in later stages collected in large masses.

130-140-hours' stage.-The most interesting phase of the entire devel- 
opment is seen at this period. The evidence met with in this stage furnishes the most decisive proof in favor of a definite relationship existing between the cyto-reticulum of the embryonic cell and the fibril bundles of the adult. Longitudinal sections present a very marked appearance of cross striations (Fig. 11, $a$; Fig. 12,a). On examination it is found that these striations are produced by a growth, principally in length, of the deposits on the cyto-reticulum of previous stages (Fig. 9, a; Fig. 3,a). These heavily-stained bands stand out as clearly as if stamped. with a die. Sections at this period present all gradations of striations as may be seen from Figs. 11 and 12. The transverse strands of the cyto-reticulum are not very prominent. The tapering ends of the cells show an enormous increase in length. It is to be noted that the striations first appear in the elongated ends, at least they show a greater degree of development in this part of the cell. These markings

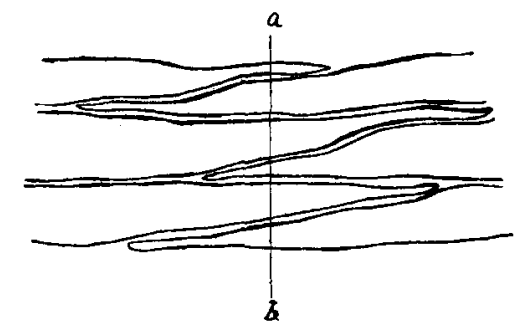

cause the ends of the cell to stand out more prominently than the other regions, and it is now very difficult to distingush cell walls in longitudinal sections. However, by means of the heavy striations, one can see how these slender projecting ends have made their way between other cells, and thus trace the formation of the syncytium-like structure of the adult tissue. In later stages, when the cell exhibits uniform striation, the course of the ends of the cells cannot be so well followed. The accompanying diagram would then represent the structure of the adult fiber in longitudinal section. This would also explain the fact that a cross section of the adult tissue, as for example, from $a$ to $b$, shows cells of widely varying diameter. A similar explanation was offered by MacCallum, 98, in the case of the striated muscle of the pig.

Fig. 12 shows the ends of two adjacent cells seen in the same section as Fig. 11, but which have apparently proceeded further in their development. The striations are well marked. In the figure several fibril bundles are represented $(a)$. The structure found here corroborates the statement that the formation of the Querscheibe starts in the ends of the cells. 
Cross sections (Figs. 13 and 14) show an increased number of the smaller meshes of the cyto-reticulum, while the deeply staining deposits (a) which are cross sections of fibril bundles have become greatly enlarged. These heavily staining patches are best developed toward the periphery of the cell. The nucleus is roughly oval in outline.

From this structure to that of the adult is but a step. While all the intermediate stages between this and the adult were not examined, sections from stages beyond this up to the eighth day, showed the same structure in various degrees of development. In the adult the sarcoplasmic discs are better developed. The Querscheibe are broader and resemble thick, flat plates. The length and diameter of the cell is greatly increased.

\section{SUMMARY.}

The facts which appear to be of importance as set forth in the foregoing, are as follows:

1. The cytoplasm of the early embryonic heart cell is traversed by an irregular network, the nodes of which are marked by heavily staining deposits.

2. This network tends to become more and more regular, until its strands are longitudinally and transversely disposed.

3. The heavily staining deposits on the primitive network develop into the Querscheibe of the adult fibril bundle.

4. The longitudinally disposed lines of the network represent the axes of the fibril bundles of the adult.

5. The sarcoplasmic discs of the adult develop from the inter-reticular cytoplasm of the embryonic cell.

\section{General Discussion on the Relation Between the Cytoptasm and the Fibril Bundees.}

According to Ranvier, 89, the myocardium of the mammal is composed of rhomboidal branching cells. The nucleus is centrally placed and is surrounded by a granular mass stretching out in the axis of the cell. Surrounding this granular mass is the contractile element which shows longitudinal and transverse markings. This element is the fibril and is made up of successive segments having the same structure as voluntary muscle.

Koelliker, 02, describes the mammalian heart muscle as composed of an interlacing network of cells having centrally placed nuclei. The contractile substance, as in voluntary muscle, consists of fibril bundles, the so-called "Muskelsäulchen," which show a definite transverse striping. 
Of the later workers, Godlewski's, o2, description is interesting, because of his denial of cell structures in the heart muscle of the rabbit. According to him the heart muscle is a syncytium in which there is no cell demarcation. The contractile substance is the fibril which shows the various markings described by other authors.

Thus, in general, in addition to the above, the work of investigators goes to show that the contractile substance in the muscle tissue is the fibril. A number of these in turn compose the fibril bundle. Workers are not agreed as to the origin of the fibril bundles. The older hypothesis that they are extra-cellular structures is now refuted and the generally accepted opinion is that they are intracellular.

Two current views exist as to the nature of the fibril bundles. The first is that these structures are coagulation products, and that the living cell contains neither cyto-reticulum nor fibrils (Englemann, 73-8I). The second view is that the fibrils are differentiated structures which are formed in the living cell. The latter theory is the one which the results of many workers seem to verify. Of the latest workers Eycleshymer, 04, reports having observed the fibrillæ (fibrils) in the living muscle cells of larval necturus.

Concerning the origin of the fibrils, there are what is known as the network theory and the fibrillar theory. The upholders of the network theory maintain that the muscle cell contains a contractile reticulum, the longitudinal threads of which form the fibrils, the meshes being filled with a more fluid substance. Others consider that the fibrils are produced by the coagulation of the fluid substance, as a result of the action of various reagents. Later work apparently refutes the latter idea. The advocates of the fibrillar theory maintain that the fibrils are the contractile elements, and further, that they arise independently of the cyto-reticulum. Eycleshymer's, 04, work on necturus, supports this idea, and Godlewski, o2, in his work on the striated muscle cell of the rabbit, has been able to find no trace of a cytoplasmic network.

In the theory urged by MacCallum, 98 , we have a combination of the network and the fibrillar theories. In this author's words (p. 211), "It simplifies the conception of the structure of striated muscle fiber greatly, to consider the fibril bundles and the membranes bounding the compartments in the sarcoplasm as derived from the primitive network found in the muscle cells of very young embryos." (p. 209) "This network tends to become more and more regular until the meshes are of the form of large discs. Some of these break up into smaller ones and in the nodal points of the network there is an accumulation or differentiation 
of its substance, giving rise to longitudinally disposed masses. These become what in the adult are known as fibril bundles and the discs are the sarcoplasmic dises."

Now the question is, How do these theories apply to the conditions met with in the heart muscle of the chick? We will consider MacCallum's theory first.

The occurrence of the breaking up of the meshes of the cyto-reticulum into smaller parts was noticed in the case of the chick. That the fibril bundles arise from the center of the meshes at the nodal points of the network appears, however, to be untrue. Here, in fact, it seems that the nodes of the original network mark the positions of the fibril bundles; in other words, that the primitive longitudinal threads develop into these structures. To illustrate, the accompanying figure represents a diagrammatic cross-section of the cyto-reticulum. The unbroken lines represent the threads of the original network. The circular masses at the inter-

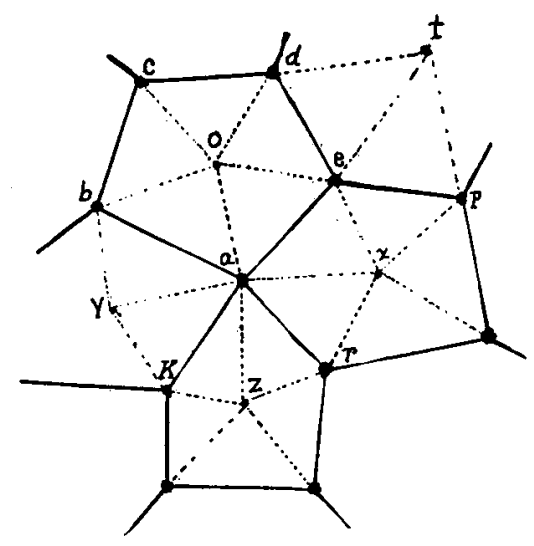

sections of this network ( $a, b, c$, etc.) represent the heavily-stained deposits. The dotted lines divide the large meshes or discs into the "small sarcoplasmic discs" of MacCallum (boc, cod, etc.). Now according to the author just mentioned, a fibril bundle arises in the center of any large dise at the point of intersection of the dotted lines $(o, x$, etc.). The full lines would then represent boundaries of sarcoplasmic discs. However, in the case of the chick the facts seem to indicate that the fibril bundles arise at the points of intersection of the lines of the original network $(a, e, b$, etc.). Then the sarcoplasmic disc surrounding any one particular fibril bundle, as, for example, that one the cross section of which is represented by $a$, would be the area bounded by yboexrzk. 
The writer's preparations clearly show that the nodal points of the original cyto-reticulum of the embryonic heart cell are marked by more heavily staining deposits, both in longitudinal and in cross section (Figs. $3,4,5,6)$. The deposits can be followed in successive stages, and are always identified with the longitudinal and transverse threads of the network. Eventually they develop into the Querscheibe, and the longitudinal threads of the network become the axes of the fibril bundles of the adult tissue. If this be true, the fibril bundles cannot originate from the centers of the meshes seen in cross sections of the cyto-reticulum.

Suppose now that fibril bundles were to form at the points $a$ and $e$ of the diagram. Then we would have the two fibril bundles surrounded by one set of sarcoplasmic discs (odtpxrzkyb), a condition sometimes found in the adult; also mentioned by MacCallum, 97 (p. 613), in the human heart muscle. However, were these two sets of sarcoplasmic discs to become separated by a plane of division along a line from 0 to $x$, then each fibril bundle would have its own set of sarcoplasmic discs, the structure more generally met with in the adult.

If the fibril bundle in its development follows the method suggested by the writer, another difficulty is encountered with the results of MacCallum's, 98, work. This worker states that the transverse membranes of the cytoplasmic reticulum of the myoblasts of man and of pig (represented in the chick in Fig. 8, $a$; Fig. 9, $c$ ), give rise to Krause's membrane in the adult. Attention is called to the fact that (as seen in Figs. 8 and 9) the intersections of these transverse lines with the longitudinal lines of the reticulum mark the positions of the deeply-staining substance which later becomes the Querscheibe. Now, in the adult, Krause's membrane is found as a narrow transverse band across the lightly-staining portions of the fibril bundles, and not at all connected with the Querscheibe. Thus it is readily seen that MacCallum's explanation of the formation of this structure does not apply in the case of the chick, nor could its origin be determined satisfactorily, for, as was remarked in another place, it is not very well differentiated in the heart muscle of the adult chick.

At this point it is interesting to consider the work of Eycleshymer, 04, on the striated muscle cell of Necturus. This author states that in the study of the striated muscle cells of Necturus, he has been unable to find any evidence of a definite or fixed relation between the cytoplasmic network and the fibrillæ (fibrils). Further, as serious objection to the existence of such a relation, he says that the fibrillæ are unstriated for some time after their appearance. 
In the case of the chick, however, the above is not true. For if we consider the longitudinal threads of the network of the stage represented in Figs. 8 and 9 , as the incipient fibril bundles, then the deposits marking the intersections of the threads would represent the striations, since later these develop into the Querscheibe of the adult tissue. The question is just what is to be understood by "first appearance of fibrillæ." If by this we mean the earliest stage in the development of the fibril bundles at which there is any resemblance to the adult structure, we may say that the fibrillæ are striated from the start in the chick.

With reference to another point in this connection, the writer here quotes a passage from the same author, pp. 298, 299: "A point of capital importance is found in the fact that in Necturus, Amia Lepidosteus . . . . as my own observations show, and in other forms as Kaestner, 92, has found, the beginning of fibrillation is coincident with the first contractions. The movements of the embryo first begin in the anterior of the mid-dorsal myotomes and in these the myoblasts are first fibrillated. The above considerations led the writer to support the theory that the fibrillæ are pre-existent structures and represent the principal contractile element."

The same argument cannot be applied to the heart muscle of the chick, because the first contractions occur at the time when about 15-17 myotomes have been formed in the embryo. As may be seen from the representation of the heart muscle cell at this stage (Fig. 1), no structure which might be truly called a fibril is present. The first appearance of anything that in the faintest way resembles the adult is not seen before the 120-130-hours' stage (Figs. 8 and 9).

If the fibrillæ are not pre-existent structures, what then are the contractile elements in the very early embryonic stages? In view of the above facts the explanation offered by MacCallum, 97 (p. 620), seems plausible. This author suggests that the contractile elements in the early embryonic heart would be represented by the irregular network seen at that stage before true fibrils exist. This, it seems, would lend support to the writer's suggestion in regard to the origin of the fibrils. For if, as MacCallum says, the cytoplasmic network -represents the contractile element in the early stages, it seems reasonable at least to consider the longitudinal lines of this network as developing into the fibrils rather than to suppose the latter to arise from accumulations of the network-substance in the cytoplasm contained between the meshes.

In conclusion, the results of the work embodied in this paper point to the existence of a definite relationship between the cytoplasmic reticulum of the early embryonic cell and the fibril bundles of the adult cell. 


\section{LITERATURE CITED.}

EngelmanN, Th. W., 73-81--Mikroskopische Untersuchungen über die quergestreiften Muskelsubstanz. I u. II Pflügers Arch., Bd. VII, 1873.

Kontraktilität und Doppelbrechung. Pflügers Arch., Bd. XI.

- Neue Untersuchungen über die mikroskopischen Vorgänge bei der Muskelkontraktion. Pflügers Arch., Bd. XVIII, 1878.

Mikrometrische Untersuchungen an kontrahierten Muskelfasern. Pflügers Arch., Bd. 26, 1881.

- Bemerkungen zu einen Aufsatz von Fr. Merkel: Ueber die kontraktion der quergestreiften Muskelfaser. Pflügers Arch., Bd. 26, 1881.

- Ueber den faserigen Bau der kontraktilen Substanz mit besonderer Berücksichtigung der glatten und doppelt schrag gestreiften Muskelfasern. Pflügers Arch., Bd. 25, 1881.

ErCleshymer, A. C., 04.-The Cytoplasmic and Nuclear Changes in the Striated Muscle Cell of Necturus. Am. Journ. Anat., Vol. III, No. 3.

GoDLEwski, E., 02.-Die Entwickelung des Skelet- und Hertzmuskelgewebe der Säugethiere. Arch. f. mikr. Anat., Bonn, 1902, Bd. LX.

Koelriker, o2.-A. Koelliker's Hanḋbuch der Gewebelehre des Menchen. 6. Anlage, p. 609, Leipz., 1902.

KoLossow, A., 92. -Ueber eine neue Methode der Bearbeitung der Gewebe mit Osmiumsäure. Zeitschr. f. wissenschafti. Mikroskopie Bd. 9, 1892, p. 38.

MacCaILUM, J. B., 97- - On the Histology and Histogenesis of the Heart Muscle Cell. Anat. Anz., Jena, 1897, Bd. XIII, S. 609-620.

98. - On the Histogenesis of the Striated Muscle Fiber and the Growth of the Human Sartorius Muscle. Johns Hopkins Hosp. Bull., Balto., 1898, Vol. IX, pp. 208-215.

RanviER, 89.-Traité technique d'histologie. Paris, 1889.

\section{EXPLANATION OF FIGURES 1 TO 17.}

\section{AbBreviations Used.}

$a=$ Heavily staining deposits at the nodal points of cyto-reticulum of early embryonic cells.

$b=$ Karyosome masses.

$c=$ Transverse threads of cyto-reticulum.

$a=$ Nucleus.

$b l=$ Lightly staining bands on the fibril bundles.

$s d=$ Small sarcoplasmic discs of MacCallum, 97 .

$s b=$ Sarcoplasmic disc.

$s a=$ Part of a sarcoplasmic disc seen in longitudinal section.

$b n=$ Cyto-reticulum of the interior of the adult cell.

$b x=$ Points of intersection of longitudinal threads with transverse threads, not marked by heavlly staining deposits.

$\iota a=$ Enlarged cytoplasmic area. 

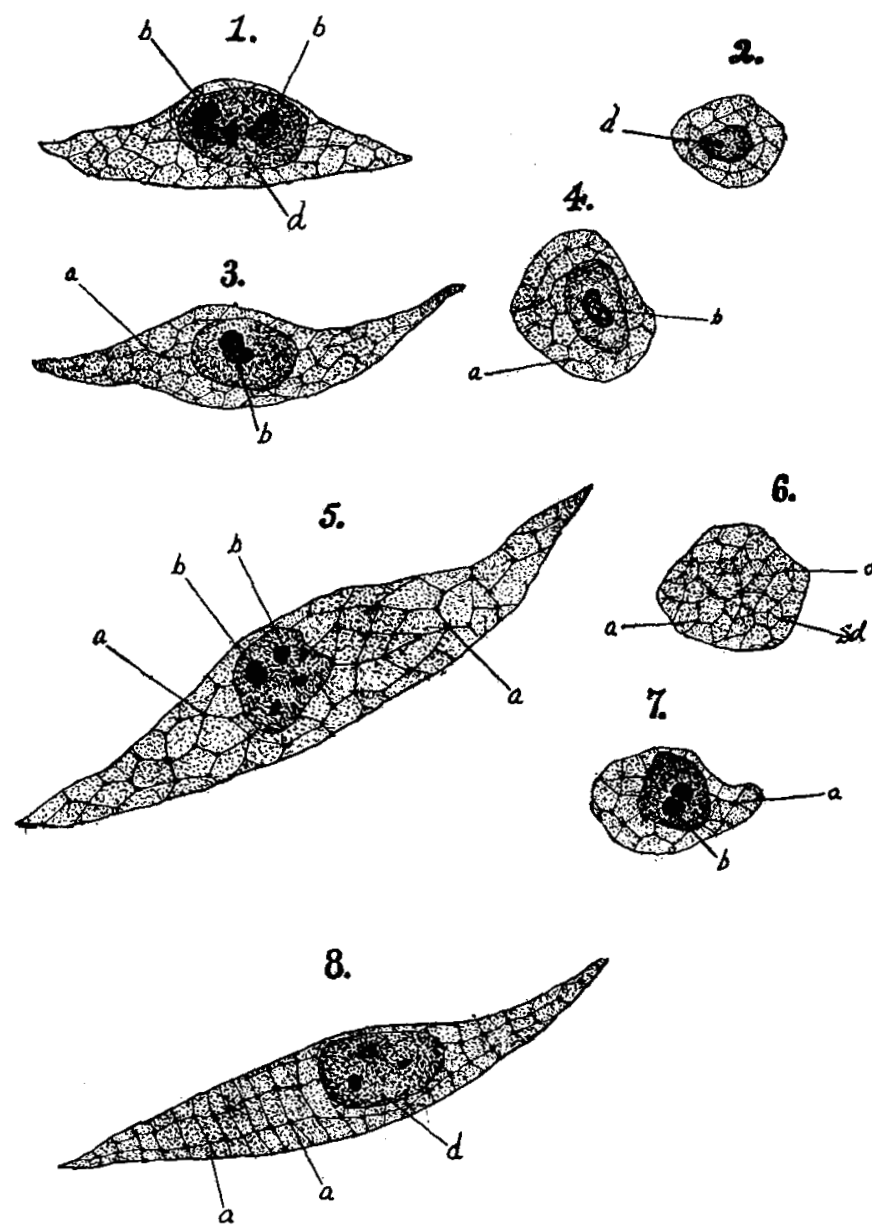

FIGs. 1 To 8.

The accompanying figures are camera luclda drawings made at table level. In all cases the magnification is about 2000 diameters.

Fro. 1. Longitudinal section of heart muscle cell from a 30-hour embryo. The cytoplasm shows an irregular network.

Fre. 2. Cross section at 30-hour stage.

Fre. 3. Longitudinal section, 72-hour stage.

Frg. 4. Cross section, 72-hour stage.

Frg. 5. Longitudinal section, 96-hour stage.

Fras 6 and 7 . Cross sections, 96-hour stage; Fig. 6, above or below the nucleus; Fig. 7 , through the region of the nucleus.

Fro. 8. Longitudinal section, 120-130-hour stage. 


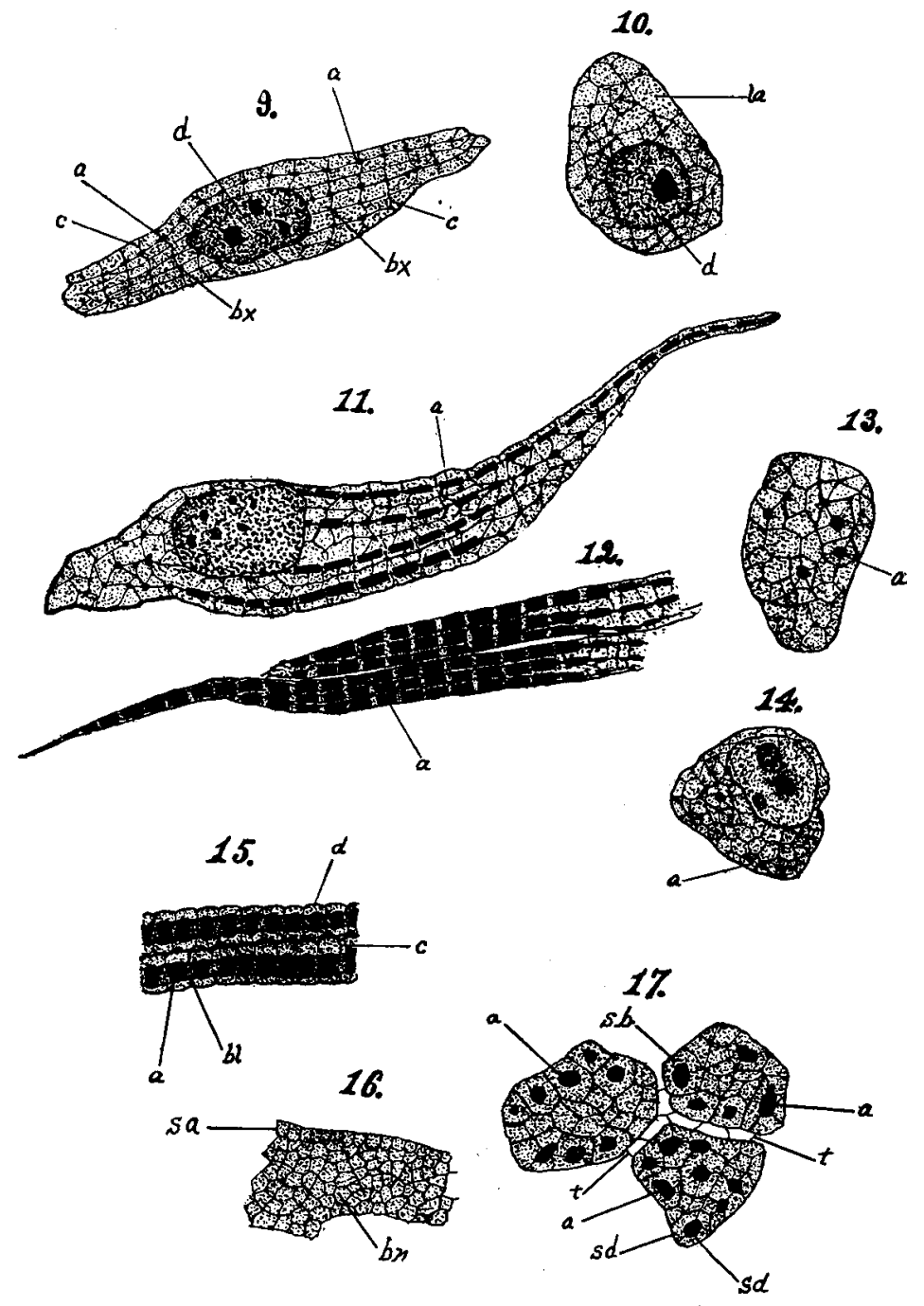

Figs. 9 тo 17.

The accompanying figures are camera lucida drawings made at table level. In all cases the magnification is about 2000 diameters.

Fia. 9. Longitudinal section, 120-130-hour stage.

Fia. 10. Cross section, 120-130-hour stage.

Fias. 11 and 12 . Longitudinal sections, 130-140-hour stage.

Fras. 13 and 14. Cross sections, 130-140-hour stage.

Fra. 15. Longitudinal section of two adjacent fibril bundles of adult tissue.

Fie. 16. Longitudinal section through the reticular structure found in the center of the adult cell.

Fir. 17. Cross section of the aduit heart muscle cell. 